\title{
Inheritance of attributes in natural concept conjunctions
}

\author{
JAMES A. HAMPTON \\ The City University, London, England
}

\begin{abstract}
Attributes defining pairs of concepts (e.g., SPORTS-GAMES) and their conjunctions (e.g., SPORTS THAT ARE ALSO GAMES) were generated and rated for their importance for defining each concept and conjunction. The results support a model in which a composite prototype for the conjunction is formed as the union of the constituent attribute sets, subject to two constraints: (1) attributes must have a sufficiently high average importance across the two concepts, and (2) necessity and impossibility of attributes is always inherited. In regression analyses, those concepts identified by Hampton (1985b) as being dominant in determining item typicality in conjunctions were again dominant in determining attribute importance and also had greater numbers of important attributes. There was limited evidence of noncompositionality for familiar concept conjunctions. Finally, degree of conflict between the attributes of one concept and those of the other had an independent effect on attribute importance for conjunctions.
\end{abstract}

This study is concerned with how people combine everyday language concepts in the process of understanding conjunctive phrases, such as "a sport that is also a game." The problem of natural concept conjunction has attracted much recent interest because of its strong theoretical importance. The problem lies in determining what happens to the natural ill-defined concepts we use in everyday speech and thought, when they are subjected to the logical operation of conjunction. A formal treatment of the logic of ill-defined sets was developed by Zadeh (1965) in the form of fuzzy logic, which assumes that membership in a class is a matter of degree, expressed by a continuous variable that can have values between 0 and 1 . Fuzzy logic provides sets of rules by which such operations as negation, conjunction, and disjunction can be applied to simple class membership propositions. These rules take the form of functions by which the truth value of a complex expression may be evaluated, given the truth values of its constituent parts. Because of its parallel assumptions, fuzzy logic was considered by many to support the psychological model of concepts proposed by Rosch (1975) and others, a model that views concepts as consisting of a prototype representation with an allowable degree of distortion (see Hampton, 1979, 1981; Rosch \& Mervis, 1975). According to prototype theory, the prototype for many natural object classes is a set of

\footnotetext{
This research was conducted while the author was on sabbatical at Stanford University, whose hospitality is gratefully acknowledged. It was made possible by a personal research grant from the British Academy and by a Nuffield Foundation Social Science Fellowship. A paper based on the work described here was presented to the British Psychological Society Conference, London, in December 1985. Thanks are due to Larry Barsalou, Herb Clark, Joe Danks, John Gardiner, Mark Gluck, Phil Johnson-Laird, Greg Murphy, and an anonymous reviewer for helpful comments on the research and on earlier drafts of the manuscript. Re quests for reprints should be addressed to: James A. Hampton, Psychology Division, Department of Social Science and Humanities, The City University, Northampton Square, London ECIV OHB, England.
}

attributes that define the central tendency of members of the class, based on the family resemblances of members. Items may vary in their similarity to the central prototype, according to the relative number of matching attributes that they possess. To define membership in the class, one places a flexible criterion on the scale of similarity to the prototype, so that membership can be a matter of degree and depends on the degree of similarity of an item to the class as a whole. Typicality of items in the class-a variable introduced by Rosch (1975) to capture the common intuition that some class members are more representative than others-is defined in terms of the same underlying similarity variable, as determines degree of membership.

The close relation between fuzzy logic and prototype theory was shaken when Osherson and Smith (1981) showed that Zadeh's (1965) fuzzy logic rules fail to match people's intuitions about the conjunction of natural concepts. Since their article appeared, a considerable amount of discussion has centered on the implications of this failure.

Osherson and Smith $(1981,1982)$ showed that there is no generally applicable, simple function that will map the degree to which any item belongs in each of two concepts (e.g., PET and FISH) to the degree to which it belongs in their conjunction (i.e., PET FISH). Zadeh's (1965) proposed minimum rule-that conjunctive membership is the lesser of the two constituent values-matches the intuition that items should only belong in a conjunction if they also belong in both constituent sets. However, when typicality judgments are considered, the minimum rule can clearly be broken (e.g., GUPPY and GOLDFISH are better examples of the conjunction PET FISH than they are of either constituent alone). Zadeh's alternative rule for conjunction-a multiplication of the two constituent truth values-fares even worse, since it would predict that an item's membership (and hence typicality) in a conjunction must always be lower than its membership in either 
constituent. In a second article, Osherson and Smith (1982) proved formally that typicality in the conjunction of two concepts could not be a simple function of the two constituent typicalities. At the very least, a third parameter must be involved in the function: namely, the positive or negative contingency between the two constituent concepts. Osherson and Smith concluded that the whole formal basis of prototype theory, whereby class membership is not all-or-none but rather depends on degree of similarity of an object or class to the concept prototype, is thrown into serious doubt. In particular, they suggested that intuitions of typicality and judgments of class membership may in fact depend on different sources of semantic information and, hence, cannot be subsumed under one theory in the way the prototype model tries to do.

In response to this challenge, two very different positions have been taken to defend prototype theory. On the one hand, there have been defenders of the fuzzy logic approach, with its emphasis on the extensional aspect of concepts (i.e., the set of objects that the concept names and the respective typicality of each object). Jones (1982) argued for an ordinal function that could account for item typicality in conjunctions through a rescaling of the rank order of items that actually fall in the extension of the conjunction. Zadeh (1982) argued for a variety of fuzzy logic operators, whose appropriateness would be locally determined by the concept domain. Turksen (1984) proposed that the fuzzy operator itself should be treated as fuzzy, so that the operation of conjunction merely places an upper and a lower bound on possible item typicality (see also Ginsberg, 1984). All of these proposals maintain the view that it should be possible to find a function or set of functions that would predict how well an item fits a conjunction $A \& B$, given the fit of the item in the constituent concepts A and B separately, and given access to other extensional information (e.g., what other objects are to be found in the conjunction).

On the other hand, a number of authors have proposed a quite different mechanism for fuzzy set conjunction. Cohen and Murphy (1984), for example, argued that the prediction of typicality in a conjunction cannot be made without consideration of the intensions of the two concepts (i.e., the attributes that are typically shared by class members). Fuzzy logic, which, like classical logic, operates in the extensional domain, does not address how the meanings of concepts modify each other when they combine. Hampton (1983) also argued for the intensional approach, showing how, in principle, the phenomena described by Osherson and Smith (1981) can be explained by an interactive process of combining intensions. The process can be illustrated by considering the example of PET FISH. PET FISH possess some attributes of PETS that are not generally true of FISH (e.g., a domestic environment), and some attributes of FISH that are not generally true of PETS (e.g., cold and slimy skin). Thus, the process of forming an intension for the conjunction (called a composite prototype, Hampton, 1983) involves interactions whereby only some attributes of each constituent are true of the conjunction. The conjunction, there- fore, will not possess all the attributes of either constituent. An exemplar such as GUPPY, therefore, can make a perfect match with the conjunctive concept, while at the same time lacking relevant attributes of either constituent. Hence, its typicality will be greater for the conjunction than for either constituent. A similar approach has been adopted by Thagard $(1983,1984)$. Smith and Osherson (1984) themselves argued for the intensional combination of concepts, and they developed a detailed model of simple adjectival modification of noun concepts, such as BROWN APPLES. However, they differed from Hampton $(1983,1985 \mathrm{a}, 1985 \mathrm{~b})$ and Thagard $(1983,1984)$ in limiting their model to the determination of the typicality of items already in the conjunction. The way in which membership in the conjunction is determined, Smith and Osherson claim, still relies on the classical Boolean rule for conjunction.

More extreme views within the intensional approach have been taken by Murphy and Medin (1985) and by Lakoff (1985), who argue that concepts are not compositional in any simple linear sense, and so the combination of concepts into conjunctions will require reference to a detailed theory or model of the world in order to determine what the resulting concept will be. Holders of this view would predict that concept combination depends critically on the particular structure of individual concepts and would aim to describe how these structured representations might interact. Although this approach makes no specific predictions in the absence of any way to represent these "mental models," the approach might expect that conjunction formation is noncompositional, that is, that the attributes of a conjunction are not simply those of the two constituents. Conjunctions should be different from the sum of their parts.

The focus of the present paper is the feasibility of a compositional intensional theory of concept combination. The aim is to specify the intension of a conjunction by identifying the rules by which it inherits attributes from its constituent concepts. The success of the model, therefore, depends upon finding appropriate inheritance rules. In order to generate some specific predictions about this process, the following model for attribute inheritance was proposed, based on earlier theoretical analyses (Hampton, 1983,1985 b).

\section{A Model for Attribute Inheritance}

The model first proposes that the intension of a conjunction is formed as the union of the constituent attribute sets. This rule corresponds to the classical Boolean definition of set conjunction, which states that members of the conjunction of two sets must have the defining features of both sets. The model presented here, however, assumes that the union applies initially to all attributes, including those that are only probabilistically related to the concept, being true of the typical members, but not of atypical members.

The second proposal is that the importance of an attribute for a conjunction (assuming the standard prototype theory, in which the attributes defining a prototype 
vary in their weight or importance for the definition) will be a rising monotonic function of its two constituent importance values. This proposal leads to two predictions. First, multiple regression analyses should show that the importance of an attribute for a conjunction can be significantly predicted from the importance of the attribute for the two constituents. Second, importance for the conjunction will involve a trade-off between the two constituent importances, and, therefore, where the average importance of an attribute for the two concepts is low (even allowing that one importance value may be fairly high), importance for the conjunction may also be low. Where an attribute is important for one constituent, but is not important for the conjunction, it is an instance of inheritance failure. (No distinction is made in the model between important constituent attributes that are not inherited at all, and those that are inherited with very low importance. Both are considered inheritance failures.)

A third proposal places two constraints on the inheritance function. One constraint is that attributes that are necessary for either constituent (i.e., common to all members) will also be necessary for the conjunction. The other, converse, constraint is that those attributes that are impossible for either constituent will similarly be impossible for the conjunction. These two inheritance rules stem from Hampton's (1983) analysis of the attribute interactions in the PET FISH example described earlier. For example, it may be necessary for PETS to have an owner but impossible for FISH to be warm and cuddly. Hence, PET FISH must inherit the former attribute, but cannot inherit the latter. The proposed impossibility constraint predicts a second source of inheritance failures, which should occur where attributes that are important for one concept are nonetheless impossible for the other, and so are not inherited by the conjunction. (The terms necessary and impossible as used here refer to a subject's intuitions about what certain things must be and what certain things cannot be. As they refer to naive intuitions, they should not be considered to carry any deeper ontological or epistemological significance.)

In Experiments 1 and 2, detailed descriptive data on the attributes commonly associated with a number of conjunctions are provided in order to test these predictions. The data also allow for a test of the noncompositional effects predicted from the theory-based view of concepts proposed by Murphy and Medin (1985). If concept combination is noncompositional, then some attributes would be important for the conjunction but not important in the intensions of either constituent.

\section{Dominance Effects}

The present work is a direct sequel to research I conducted on the typicality of items in conjunctions (Hampton, 1985b). Since the previous work is directly relevant to the current aims, I will now briefly summarize the results. The research had two main aims. The first was to test Smith and Osherson's (1984) claim, described earlier, that class membership in a conjunction is deter- mined independently of typicality. The second, broader aim was to investigate the quantitative relationship between (1) an item's typicality and membership in each of two overlapping concept classes and (2) that item's typicality and membership in the conjunction of the two classes.

Concerning the first aim, I found that there was no need to postulate independent processes for judging membership and typicality in conjunctions. This was because subjects did not follow a strict Boolean definition of conjunction. In a series of experiments, subjects rated items for their degree of membership or typicality in each of two constituent classes. A week later, they rated the same items for their degree of membership or typicality in the conjunction of the two classes. (Typicality and membership judgments were combined into a single response scale.) As predicted by the intensional model described previously, membership in the conjunctions was overextended to include items that were not in one of the sets, provided that they were good members of the other set. Thus, it appeared that similarity to a composite prototype representation of the conjunction determined both typicality and class membership in the conjunctions. Membership in the conjunctions was not based on the extensional rule requiring membership in each of the two constituent concept classes.

The second aim was to examine the relationship between constituent and conjunctive typicalities. A highly systematic relationship was observed. In 16 regression equations, across three different experiments and using seven pairs of concepts, typicality and membership in the conjunction were highly predictable from a weighted average of constituent typicalities plus a small but significant multiplicative interaction term (significant in 14 of the equations). The average fit to the data was high (multiple $R=0.97$, on average). Of particular interest for the attribute inheritance model was an unexpected finding that emerged from the regression analysis. The relative contribution of each of a pair of concepts to determining the typicality of an item in their conjunction (as measured by their beta weights in the regression equation) was frequently very unequal. For example, the weight given to item typicality in the category SPORTS was roughly twice that given to the category GAMES in determining item typicality in both SPORTS THAT ARE ALSO GAMES, and GAMES THAT ARE ALSO SPORTS. This inequality, labeled concept dominance, was repeated in the majority of the other concept pairs studied and was statistically significant in several cases. (A replication study has since confirmed the pattern of dominance observed.) The explanation offered for this dominance was couched in terms of attribute inheritance. If, as hypothesized in the model, the initial intension for a conjunction is formed from the union of the two sets of attributes (prior to interactive effects), then if one concept has a greater number of salient and important attributes than the other, the resulting composite prototype for the conjunction will bear a closer similarity to the former concept. As a direct 
result, typicality in the conjunction would be better predicted by the concept with the greater number of important attributes, as shown in the relative regression weights for the two constituent concepts. The present experiments, therefore, can be used to test this account, by using the same concept pairs as previously studied and comparing the number of important attributes possessed by the dominant and nondominant concepts in each pair.

To summarize, the general aim of this study was to pursue the intensional account of conjunction formation by exploring possible mechanisms of attribute inheritance. To date, there have been theoretical analyses of the problem, but no published studies have looked for direct empirical data on how conceptual combination might work for noun-noun combinations (for adjective-noun combinations, see Smith, Osherson, Rips, Albert, \& Keane, 1985). For the experiments described here, I used the attribute generation technique, previously employed to elucidate the family resemblance structure of prototype concepts (Hampton, 1979, 1981; McNamara \& Sternberg, 1983; Rosch \& Mervis, 1975), to discover which semantic attributes of constituent concepts are inherited by their conjunction. I propose a model of the process of combination, which makes the following predictions: Conjunctions will inherit all attributes of constituents except those attributes with low average importance across both constituents and those that are impossible for at least one constituent. Impossibility and necessity of attributes for constituents will be "propagated" to their conjunctions. The importance of an attribute for a conjunction will in general be a rising monotonic function of its importance for the two constituent concepts. Finally, the concept in each pair that is dominant in determining item typicality in the conjunction will possess a greater number of important attributes.

\section{EXPERIMENT 1}

The aim of Experiment 1 was to generate a list of attributes for each of six pairs of concepts and their conjunctions. The six pairs of concepts had previously been used in research on conjunctive typicality (Hampton, 1985b). These attribute lists formed the basis of importance ratings for constituent and conjunctive concepts in Experiment 2. Tests of the specific predictions of the attribute inheritance model were then made on the basis of these importance ratings.

\section{Method}

Design and Procedure. Four groups of subjects were employed. Each subject received a booklet with an instruction sheet cover and six pages. At the head of each page was written the name of a concept (or conjunction) in uppercase. Beneath the concept name were 10 numbered blank rows in which subjects could write attributes as short descriptive phrases. Equal numbers of subjects were randomly assigned to each of four groups. Subjects in Group 1 generated attributes to six single concepts: SPORTS, MACHINES, FURNITURE, BUILDINGS, TOOLS, and PETS. Group 2 received six other concepts, each overlapping with one of the concepts given to Group 1: these were, respectively, GAMES, VEHICLES,
HOUSEHOLD APPLIANCES, DWELLINGS, WEAPONS, and BIRDS. Group 3 received the six conjunctions of the concepts given to Groups 1 and 2, using the phrase "A that are also B" (e.g., "SPORTS THAT ARE ALSO GAMES"). Group 4 received the six conjunctions received by Group 3, except that the order of the concepts within each conjunction was reversed (e.g., "GAMES THAT ARE ALSO SPORTS"). Half the subjects in each group received one random order of the sheets within the booklet, whereas the other half were given the reverse order. The instructions were as follows:

On each of the following pages you will find a concept that names a set of things, followed by a number of blank lines. I want you to imagine that you have to define and describe the objects named to someone who is unfamiliar with them. Do this by listing on each line the attributes or properties that you feel are in any way involved in deciding if an object belongs in the named set. You may use short descriptive phrases to describe the different aspects of the concept. Take as much time as you want, and write as much as you want. Try to list at least 10 attributes for each concept. More if possible. You should spend 2-3 minutes on each concept. There are six pages in all. Remember it is attributes that you should list and not examples of the concept.

The experiment took about $20 \mathrm{~min}$.

Subjects. Forty students taking an introductory psychology course at Stanford University participated for course credit.

\section{Results}

The attributes given by each group of 10 subjects were collapsed into a single list for each concept or conjunction. (Attributes judged by the author to be very close in meaning were counted as being the same.) Thus, there were 24 lists of attributes ( 4 groups $\times 6$ concepts), each based on collapsing over 10 subjects. These lists were then collapsed further across the four groups of subjects (viz., those generating attributes for A, B, A that are also B, and $B$ that are also $A$ ) to provide a final list of relevant attributes for each concept pair. These final 6 lists were obtained by including any attribute generated by at least 3 (out of 10) subjects in any of the four groups. The resulting lists are shown in the Appendix, together with their production frequency for each of the four groups of subjects.

Although the data from Experiment 1 were not used directly to test the predictions of the model, three aspects of the data were worthy of note. First, the degree of positive or negative association between concepts within a pair could be seen in the number of common as opposed to the number of distinctive features generated. For example, FURNITURE and HOUSEHOLD APPLIANCES had few of the same attributes generated, whereas SPORTS and GAMES had many. Second, some attributes that were generated for conjunctions were not generated for either constituent. As described in the introduction, such attributes are evidence of noncompositionality. For example, PETS THAT ARE ALSO BIRDS had the attributes live in cages and talk, which were not produced by any subjects for either constituent, PETS or BIRDS. There were 14 features that were listed by at least 3 subjects for either version of a conjunction but were listed by no subject for either constituent. Also, 20 attributes were listed by at least 3 subjects for one or both constit- 
uents but were listed by no subject for either version of the conjunction. Subjects apparently do not follow the union rule in forming attribute listings. Not all constituent attributes are inherited by a conjunction, and not all conjunction attributes are inherited by the constituents. However, production frequency is not a reliable measure of the importance of an attribute for a concept. Subjects may not think to mention some attributes that they would judge to be very important if presented subsequently. (This may be particularly true of very general attributes.) Therefore, it would be unwise to assume that unlisted attributes are unimportant for either constituents or conjunctions. Also, because there were not many subjects in each group, a large random error is possible in the production frequency score as a measure. For these reasons, Experiment 2 obtained direct ratings of the importance of each listed attribute for each concept, individually and in conjunction. Direct ratings allow for a more direct and specific test of the hypothesized model of attribute inheritance.

\section{EXPERIMENT 2}

Experiment 1 provided lists of attributes for each of the six concept pairs. The lists contained all attributes that were generated in Experiment 1 by at least 3 out of 10 subjects who defined either the constituents or the conjunctive concepts. To obtain more reliable measures of the importance of each attribute for defining each concept and, hence, to investigate the principles of attribute inheritance, these attribute lists were given to new groups of subjects who rated each attribute's importance in defining a category. Importance ratings have been used before in category research (Hampton, 1979; McNamara \& Sternberg, 1983; Ortony, Vondruska, Foss, \& Jones, 1985). Hampton (1979), for instance, showed that when subjects ranked attributes for their importance in defining a category concept, the mean ranked importance correlated significantly in each category with the production frequency with which the attributes were generated. In that same study, Hampton found that attributes identified independently as being common to all category members in a sample of items had higher ranked importance than those that were true of some category members (usually the most typical ones) but not of all. One may, therefore, reasonably assume that rating attributes for importance is a meaningful task that can reveal details of conceptual structure.

\section{Method}

Design and Procedure. A booklet was prepared with a covering instruction sheet and six pages. The instructions were as follows:

On the following six pages you will find the name of a concept, and listed below it a number of attributes, some of which are ways of defining what belongs to that concept. For example, you might see

\footnotetext{
FRUIT

1. Has a pee

2. Is eaten as a snack
}

\author{
3. Is round \\ 4. Grows on trees \\ 5. Grows under the ground \\ etc.
}

Your task will be to judge to what extent each of the listed attributes is useful in defining the concept. To do this, take each one in turn and give it one of the following letters:

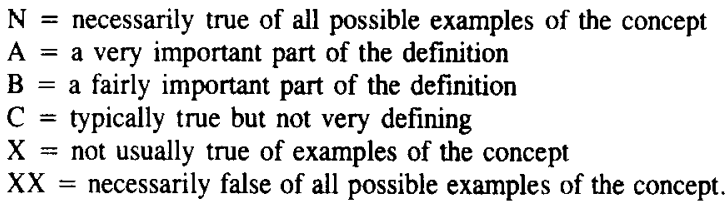

A copy of this response scale was printed on each page for easy reference. The scale was devised with the intention that the two extreme responses not only corresponded to the highest and lowest degrees of importance, but also could be used to measure the degree to which an attribute was necessary $(\mathrm{N})$ or impossible $(\mathrm{XX})$ for each concept. On each of the six following pages was a concept name and the corresponding list of attributes generated in Experiment 1, listed in a random order. There were four different versions of the booklet, each given to a different group of subjects, grouped as in Experiment 1 . For any given concept pair $A$ and B, Group 1 subjects rated the attribute lists for the A terms in each pair, Group 2 for the B terms, Group 3 for the conjunction "A THAT ARE ALSO B," and Group 4 for the conjunction "B THAT ARE ALSO A." Within each group of subjects, half rated the six concept-abbribute lists in a particular random order, and half rated them in the reverse order.

Subjects. Thirty-two Stanford undergraduate students, taking an introductory psychology course, took part in the experiment for course credit.

\section{Results and Discussion}

The results were analyzed as follows. Individual ratings were first converted into a numerical scale of attribute importance, and the scale's intersubject reliability was assessed. Second, a criterion was placed on the scale of importance, and attributes were classified as either important or unimportant for each constituent and each form of the conjunction, so that an analysis could be made of the individual pattern of inheritance of each attribute. Third, regression analyses were used to test the prediction that importance for a conjunction should in general be a rising function of importance for each constituent. Further analyses considered the frequency of $\mathrm{N}$ (necessary) and XX (impossible) responses and the extent to which necessity and impossibility are inherited from constituent attribute ratings. Finally, the results of the regression analyses, together with other descriptive statistics of the concept pairs, were used to examine the questions of concept dominance and of commutativity (i.e., the possible difference between A THAT ARE ALSO B and B THAT ARE ALSO A).

Defining the importance scale. The ratings given to the attributes were coded numerically to create a scale of importance, and the reliability of the resulting mean rated importances was tested. The ratings were converted into a numerical scale using the following coding scheme: $\mathrm{N}=+4, \mathrm{~A}=+3, \mathrm{~B}=+2, \mathrm{C}=+1, \mathrm{X}=-1, \mathrm{XX}=-2$. (No zero point was used, to provide some balance between the four positive response options and two negative ones.) Individual ratings were averaged across the 8 subjects in 
each group to give a mean rated importance between -2 and +4 for each attribute for each of its four corresponding concepts, schematically $A, B, A \& B$, and B\&A. These means are shown in the Appendix.

Reliability. The split-half reliability of the mean rated importances was obtained for the constituent and conjunctive concepts. Each group of 8 subjects was divided randomly into two equal halves, and the correlation between the mean importance scores for each half was obtained and corrected using the Spearman-Brown correction to give an estimate of the overall reliability of the full data. In addition, correlations were calculated between the two versions of each conjunction. The results are shown in Table 1.

Mean reliability was 0.89 for individual constituent concepts and 0.85 for the conjunctions, which was marginally higher than the mean correlation between the two versions of each conjunction (0.81). In 17 of the 24 attribute lists, mean rated importance also correlated significantly with production frequency in Experiment 1 . Correlations with production frequency averaged 0.62 for constituents and 0.32 for conjunctions. These relatively low values confirm the need for direct ratings of importance.

Further correlational analysis is described below in the section on prediction of attribute importance. First, however, the following section analyzes the pattern of inheritance of individual attributes for each concept pair.

Inheritance as a union of attribute sets. The proposed model of attribute inheritance suggests that as a default a conjunction inherits all of the attributes of its constituents and should have no other attributes. Violations of this rule could be of two types. First, an attribute could be important for either constituent, but not important for the conjunction (an inheritance failure). Alternatively, an attribute could be important for the conjunction but unimportant for both constituents (a noncompositional attribute).

To classify attributes as important and unimportant, an arbitrary cut-off point of 1.5 on the importance scale was used. (This criterion is the midpoint between a B and a $C$ response on the rating scale.) Because each conjunction was presented in two forms (A THAT ARE ALSO

Table 1

Split-Half Reliabilities of Mean Rated Importance and Correlations Between the A\&B and B\&A Forms of Each Conjunction, in Experiment 2

\begin{tabular}{|c|c|c|c|c|c|c|c|}
\hline \multicolumn{2}{|c|}{$\begin{array}{c}\text { Conjunctive } \\
\text { Concepts }\end{array}$} & \multicolumn{3}{|c|}{ Reliabilities } & \multirow{2}{*}{\multicolumn{2}{|c|}{$\begin{array}{c}\text { Correlation } \\
\text { Across } \\
\text { Conjunctions }\end{array}$}} & \multirow{2}{*}{$N$} \\
\hline A & B & A & $A \& B$ & B\&A & & & \\
\hline Furniture & $\begin{array}{l}\text { Household } \\
\text { Appliance }\end{array}$ & .927 & .915 & .959 & .823 & .902 & 26 \\
\hline Machine & Vehicle & .817 & .815 & .699 & .846 & .711 & 30 \\
\hline Pet & Bird & .936 & .919 & .868 & .874 & .924 & 38 \\
\hline Building & Dwelling & .874 & .930 & .830 & .897 & .835 & 29 \\
\hline Tool & Weapon & .937 & .874 & .807 & .851 & .710 & 27 \\
\hline Sport & Game & .773 & .915 & .859 & .867 & .773 & 24 \\
\hline \multicolumn{2}{|l|}{ Mean } & \multicolumn{2}{|c|}{.886} & \multicolumn{2}{|c|}{.848} & .809 & \\
\hline
\end{tabular}

Table 2

Frequencies of Attributes Important ( + ) or Unimportant ( - ) for Describing Constituents and Conjunctions, Under Strict or Lenient Scoring of Conjunctive Importance, in Experiment 2

\begin{tabular}{|c|c|c|c|c|c|c|c|c|}
\hline \multirow[b]{2}{*}{$\begin{array}{l}\text { Constituent: } \\
\text { Conjunction: } \\
\text { oncept Pair }\end{array}$} & \multicolumn{4}{|c|}{ Strict } & \multicolumn{4}{|c|}{ Lenient } \\
\hline & $\begin{array}{l}+ \\
+\end{array}$ & $\begin{array}{l}+ \\
-\end{array}$ & $\overline{+}$ & - & $\begin{array}{l}-1 \\
t \\
t\end{array}$ & $\begin{array}{l}+ \\
-\end{array}$ & - & $\begin{array}{l}- \\
-\end{array}$ \\
\hline $\begin{array}{l}\text { Furniture- } \\
\text { Household Appliances }\end{array}$ & 9 & 5 & 0 & 12 & 11 & 3 & 0 & 12 \\
\hline Machines-Vehicles & 23 & 5 & 0 & 2 & 26 & 2 & 1 & 1 \\
\hline Pets-Birds & 18 & 13 & 2 & 5 & 22 & 9 & 4 & 3 \\
\hline Buildings-Dwellings & 23 & 2 & 0 & 4 & 25 & 0 & 1 & 3 \\
\hline Tools-Weapons & 12 & 8 & 0 & 7 & 18 & 2 & 3 & 4 \\
\hline Sports-Games & 16 & 3 & 1 & 4 & 18 & 1 & 2 & 3 \\
\hline Total & 101 & 36 & 3 & 34 & 120 & 17 & 11 & 26 \\
\hline
\end{tabular}

B and B THAT ARE ALSO A), both a strict criterion and a lenient criterion of conjunctive importance were adopted; they corresponded respectively to requirements that an attribute be important for both forms (strict) or important for at least one form (lenient). Table 2 shows the resulting counts of attributes violating or not violating the union rule.

With strict scoring, there were 36 attributes that were important for at least one constituent but that were not inherited $(+/-$ columns in Table 2$)$. Of these, 17 were not rated important for either form of the conjunction (lenient scoring). Using a combined criterion, based on the average importance for the two conjunction forms, the number of inheritance failures was 26 . Therefore, a considerable number of attributes were not inherited.

There were 11 attributes rated as important for a conjunction but unimportant for both constituents $(-1+$ columns in Table 2); however, only 3 of these attributes were judged to be important for both forms of the conjunction (the strict criterion). These attributes were evidence for noncompositionality of conjunctions, since they were characteristics of the conjunction which were not derived from the constituent concepts. However, they provided only weak evidence of noncompositionality, since many of the 11 attributes were only marginally more important for the conjunction than they were for the constituents. Thus, at least some of these attributes reflected the randomness inherent in the importance ratings and did not indicate significant noncompositionality. The most convincing evidence for noncompositionality occurred for the conjunction of PETS with BIRDS, where is small and lives in a cage were important for both forms of the conjunction but were unimportant for either constituent alone.

We can conclude that although the union rule provided a fair approximation (correctly predicting some $80 \%$ of the data), there were also clear violations of the rule. Overall, conjunctions tended to have more attributes rated as important (19.6 on average) than did their constituents (17.2), but they had fewer than the union rule would predict (22.8). There were relatively few noncompositional attributes, important for the conjunctions but not for their constituents, and the majority of violations were 
cases of constituent attributes that failed to be inherited. (For cases in which only one conjunction form inherited an attribute, there was no discernible systematic pattern of which of the two forms would inherit the attributes of which constituent.) In the following analysis, I consider one reason for these inheritance failures predicted by the model: namely, that the importance of the attribute for the two constituents was on average too low.

Prediction of attribute importance. To investigate the prediction that importance for the conjunction would be a rising function of importance in each constituent, regression analyses were performed. Twelve equations were calculated to predict conjunctive importance for each version of the conjunction from the constituent importances. The regression statistics are shown in Table 3.

All of the equations accounted for significant proportions of the variance in attribute importance for the conjunctions. In 9 of the 12 equations, both constituents entered the equation at the .05 significance level (on a one-tailed $t$ test), whereas in the remaining 3 equations only one constituent was significant. The fit was generally good, with multiple $R$ ranging from 0.58 to 0.95 , with a mean of 0.81 . Multiple correlations were generally in line with the reliabilities of the dependent variables (mean $=0.85$ ). On a related $t$ test, there was no significant difference between the two $[t(11)=0.5]$. (Regressions were also performed excluding any attributes with mean ratings of less than 1.5 for both constituents. Multiple $R \mathrm{~s}$ now averaged 0.69 . All except 1 of the 12 equations were still significant, and the general pattern was largely unchanged.)

To test for alternative solutions, other terms $\left(A \times B, A^{2}\right.$, and $\mathrm{B}^{2}$ ) were tried in the regression equations. No systematic improvement in fit was obtained. In general, a weighted average of the two constituent scores appeared to be the best formula for predicting the conjunction score (allowing that in three equations the weight of one variable dropped to zero), and this formula predicted the large majority of the reliable variance in the dependent variable for most conjunctions. The hypothesized relation was, therefore, mainly supported. However, the widely differing regression weights observed within each pair of con-

Table 3

Standardized Regression Coefficients (Beta) for the Prediction of Mean Rated Importance for Each Conjunction from Mean Rated Importance of Attributes for the Constituent Concepts (A and B), Together with Multiple $R(R)$ for Each Equation

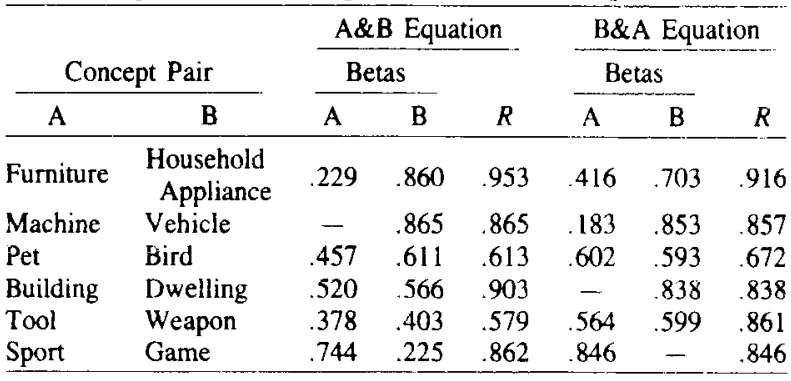

Note-Only variables entering the equation significantly at the .05 level, one-tailed, are included. Mean multiple $R=0.81$. cepts for seven of the equations was not expected. The importance of an attribute for some concepts (e.g., VEHICLES) was found to override the importance of the attribute for others (e.g., MACHINES) in forming the intension of the conjunction. In extreme cases, one concept did not enter the regression equation at all. This inequality will be discussed further in a later section in connection with the question of the phenomenon of concept dominance found for typicality judgments (Hampton, 1985a, 1985b).

The proposed model predicted that some inheritance failures should be attributable to low average constituent importance. In fact, 14 of the 26 attributes that failed on average to be inherited had one concept importance between 1.5 and 2 on the scale, and the other very low, so that an averaging function would give them an importance for the conjunction well below the criterion level (1.5). At least half of the inheritance failures may, therefore, have been due simply to generally low importance for the constituent concepts.

Necessity and impossibility. Two constraints on attribute inheritance proposed by the model were necessity and impossibility. In the case of PET FISH, for example, it was postulated that it may be necessary that pets should have an owner and that fish should have gills, and that this may explain why PET FISH inherit both attributes, rather than being free (as most fish are) and having lungs (as most pets do). The converse argument is that it is impossible for fish to be warm and cuddly, and so this attribute of PETS fails to be inherited.

To provide data to test these two hypotheses, I scored each attribute in terms of whether any subjects had given it $\mathrm{N}$ or XX ratings for each of the four concepts. $\mathrm{N}$ and $\mathrm{XX}$ ratings were then considered separately in parallel analyses. Let us first consider the $\mathrm{N}$ ratings. The hypothesis is that for cases in which either constituent received an $\mathrm{N}$ rating, then the conjunction would be rated $\mathrm{N}$ also. Because the frequency of $\mathrm{N}$ ratings was relatively low, attributes were counted as being given an $\mathrm{N}$ rating using a lenient criterion of 1 or more subjects giving an $\mathbf{N}$ response. This lenient criterion, however, necessitated excluding some items. Cases in which only a single subject in one of the groups gave an $\mathrm{N}$ rating may represent purely maverick responses, yet they would count as evidence against the hypothesis that there is a direct match between degree of necessity in a conjunction and degree of necessity in a constituent. To avoid this problem of inappropriately counting marginally necessary attributes as evidence against the hypothesis, I included only those attributes with either no $\mathrm{N}$ responses in any group or those with at least three $\mathrm{N}$ responses summed across all four groups. The total of 174 attributes was thus reduced to 115. Each of these remaining attributes was then entered into a two-way cross tabulation. Attributes were first divided into those having at least one $\mathrm{N}$ rating (1) for both constituents, (2) for only one constituent, or (3) for neither constituent. Second, they were classified into those with at least one $N$ rating (1) for both versions of the 
Table 4

Cross Tabulations of Items Given Necessity (N) and Impossibility (XX) Ratings for Constituent Concepts and Conjunctions in Experiment 2

\begin{tabular}{lccc}
\hline & $\begin{array}{c}\mathrm{N} \text { in Both } \\
\text { Conjunctions }\end{array}$ & $\begin{array}{c}\mathrm{N} \text { in Only One } \\
\text { Conjunction }\end{array}$ & $\begin{array}{c}\mathbf{N} \text { in Neither } \\
\text { Conjunction }\end{array}$ \\
\hline $\mathrm{N}$ in Both A and B & 32 & 9 & 1 \\
$\mathrm{~N}$ in A or in B (Not Both) & 30 & 7 & 0 \\
$\mathrm{~N}$ in Neither A Nor B & 2 & 0 & 34 \\
& $\mathrm{XX}$ in Both & $\mathrm{XX}$ in Only One & $\mathrm{XX}$ in Neither \\
& Conjunctions & Conjunction & Conjunction \\
\hline $\mathrm{XX}$ in Both A and B & 0 & 0 & 0 \\
$\mathrm{XX}$ in A or in B (Not Both) & 14 & 0 & 1 \\
$\mathrm{XX}$ in Neither A Nor B & 1 & 0 & 139 \\
\hline
\end{tabular}

conjunction, (2) for only one version, or (3) for neither version. Table 4 shows the cross tabulation.

Violations of the necessity constraint were very few. There was only one attribute that was necessary for both A and B but not necessary for either form of the conjunction (lets people go faster than without it for VEHICLES THAT ARE ALSO MACHINES), and there were only two attributes necessary for both conjunctions but necessary for neither constituent (is large for BUILDINGS THAT ARE ALSO DWELLINGS, and is found in buildings for FURNITURE THAT IS A HOUSEHOLD APPLIANCE).

There was, therefore, good evidence that necessity of attributes is inherited from constituents and, furthermore, that these inherited attributes are the only source of necessary conjunctive attributes. This conclusion was confirmed by an analysis of those attributes that had $\mathrm{N}$ ratings for only one of the two constituents. Table 5 shows the frequency of $\mathrm{N}$ ratings for the conjunctions as a function of frequency of Ns for the single constituent. There was a strong positive correlation between the two frequencies $(r=0.74, n=73, p<.001)$.

To analyze the XX ratings, an identical cross tabulation was made, the results of which are also shown in Table 4. Frequencies of using the XX response were much lower. Nineteen attributes were excluded from the analysis because their total numbers of XX ratings were either 1 or 2 . Of the remaining 15 attributes given an $\mathrm{XX}$ rating for one or both constituents, all except one (is used for construction for TOOLS THAT ARE ALSO WEAPONS) had an XX for at least one of the conjunctions. This inheritance of impossibility, in fact, explains six more of the violations to the union rule previously noted. For example, MACHINES have an attribute replaces people with mean importance 2.0. However, this attribute received $2 \mathrm{XX}$ responses for VEHICLES. Mean importance for the conjunction was 0 and 0.625 , with two $\mathrm{XX}$ ratings. Two further examples occur for the conjunction of PETS and BIRDS. BIRDS have the attributes migrates and is free, which were judged impossible for PETS and, therefore, impossible for BIRDS THAT ARE ALSO PETS.

Additional data on the question of necessity and impos- sibility were obtained from a subsidiary study in which four groups of subjects were asked to estimate the percentage of category members (for each constituent and each form of the conjunctions) possessing each attribute on the list. (A small number of attributes such as has various colors were excluded, since they apply to the category as a whole and not to individual members.) The design was identical to that of Experiment 2, and 10 subjects performed in each of the four groups. A count was made of the relative frequency of $100 \%$ and $0 \%$ frequency judgments. These judgments can reasonably be equated with $\mathrm{N}$ and $\mathrm{XX}$ responses in the present task. Once again, only attributes with either zero ratings or more than two ratings of $100 \%$ or $0 \%$ were used in the analysis. The results shown in Table 6 confirmed the strong tendency of necessity and impossibility to be inherited.

None of the 122 attributes given a $100 \%$ rating for either or both constituents failed to have a $100 \%$ rating for at least one conjunction, and 109 of them had a $100 \%$ rating for both forms. Of the 19 attributes given a $0 \%$ response to either or both constituents, all but 1 had a $0 \%$ response for at least one conjunction. The one violation was talks, which was rated as possible for PET BIRDS but was given zero frequency ratings for both PETS and BIRDS. Importance ratings and frequency estimates, therefore, agreed in showing how necessity and impossibility are "propagated" from constituent concepts to their conjunctions.

Dominance. This section considers the conceptdominance effect, whereby two concepts contribute unequally to the determination of the typicality of items in

Table 5

Mean Frequency of $\mathbf{N}$ Ratings Given to Conjunctions for Attributes with an $\mathbf{N}$ Rating for Only One of the Constituents, in Experiment 2

\begin{tabular}{cccr}
\hline $\begin{array}{c}\text { Frequency of } \\
N \text { Ratings Given } \\
\text { to Constituent }\end{array}$ & $\begin{array}{c}\text { Mean Frequency of } \\
\text { N Ratings Given } \\
\text { to Conjunction }\end{array}$ & $S D$ & $N$ \\
\hline 1 & 0.52 & 0.70 & 46 \\
2 & 0.92 & 0.73 & 12 \\
3 & 2.40 & 1.33 & 10 \\
4 and 5 & 3.40 & 1.92 & 5 \\
\hline
\end{tabular}

Note $-N=$ Number of attributes. 
Table 6

Analysis of Data from an Unpublished Study Showing Numbers of Attributes

Given $100 \%$ or $0 \%$ Frequency Estimates for Relative Number of Category Members Possessing the Attribute

\begin{tabular}{lccc}
\hline & $\begin{array}{c}100 \% \text { in Both } \\
\text { Conjunctions }\end{array}$ & $\begin{array}{c}100 \% \text { in Only One } \\
\text { Conjunction }\end{array}$ & $\begin{array}{c}100 \% \text { in Neither } \\
\text { Conjunction }\end{array}$ \\
\hline $100 \%$ in Both A and B & 60 & 2 & 0 \\
$100 \%$ in A or in B (Not Both) & 49 & 11 & 0 \\
$100 \%$ in Neither A Nor B & 4 & 0 & 18 \\
& $0 \%$ in Both & $0 \%$ in Only One & $0 \%$ in Neither \\
& Conjunctions & Conjunction & Conjunction \\
\hline $0 \%$ in Both A and B & 1 & 0 & 0 \\
$0 \%$ in A or in B (Not Both) & 11 & 6 & 0 \\
$0 \%$ in Neither A Nor B & 2 & 0 & 109 \\
\hline
\end{tabular}

their conjunction. The six conjunctions used here were previously studied in the context of a typicality rating experiment (Hampton, 1985b). Their relative dominance as measured in that study was taken as the explicandum, and the data of the present experiments on attribute importance were used to try to account for that pattern of dominance. The proposed model predicts that the dominant concept in each pair should have a greater number of important attributes.

The dominant and the nondominant concepts in each part were compared on six different measures of the attribute data, to determine what aspects of the present data would correlate with the distinction between dominant and nondominant concepts. From Experiment 1, these measures were (1) the mean number of attributes listed per subject, and (2) the number of different attributes (types not tokens) listed by at least 3 people. From Experiment 2, the measures were (3) the mean rated importance of all attributes, (4) the number of attributes with mean ratings as high as 1.5 , (5) the regression weights in the equation predicting importance for the conjunction, and (6) the variance in mean importance scores within the lists of attributes.

Dominant concepts for each conjunction were identified on the basis of previous results (Hampton, 1985b) as, in each case, HOUSEHOLD APPLIANCES, VEHICLES, BIRDS, DWELLINGS, WEAPONS, and SPORTS. Results of comparing dominant and nondominant concepts are shown in Table 7, together with related $t$ tests of the significance of each difference $(d f=5)$.

Dominant concepts had significantly higher mean rated importance scores for the attribute lists as a whole and significantly more attributes with importance scores greater than 1.5 than did nondominant concepts. This result is exactly as predicted by the model. If the intension for the conjunction depends on the combination of the two constituent sets of attributes, then dominance in typicality may result because one concept has a greater number of important attributes. Table 7 also shows that the dominant concepts had significantly higher regression weights for predicting attribute importance for the conjunction. In fact, in 11 of the 12 equations, the dominant concept for typicality was also the dominant concept for predicting attribute importance. This additional close correspondence between the patterns of dominance in the two different aspects of concept structure was not anticipated, but is fully consistent with the proposed model. An account will be offered in the General Discussion.

The dominance effect was not associated with the number of types or tokens of attributes generated in Experiment 1 (confirming perhaps that direct rating is more reliable as a measure of attribute importance than is production frequency, but also providing no evidence that important attributes of the nondominant concept were more likely to have been omitted from the final list). Finally, dominance was not associated with differential variance between the two constituents. In fact, the nondominant concepts had a slightly greater variance on average.

Commutativity. The study by Hampton (1985b) also showed that conjunctions are noncommutative in the sense that greater weight is given to a concept for predicting typicality in a conjunction when the concept occupies the qualifier position than when it is in head noun position in a conjunctive phrase. Although not previously mentioned in the light of attribute inheritance, the data of Experiment 2 can also be analyzed to test this effect. Thus, we might expect that the importance of an attribute for

Table 7

Pattern of Dominance Between Concept Pairs on Various Measures Taken from Experiments 1 and 2, Showing Value of $t$ Where There is a Significant Difference Between Dominant and Nondominant Concepts

\begin{tabular}{lccr}
\hline \multicolumn{1}{c}{ Measure } & Dominant & Nondominant & $t$ \\
\hline $\begin{array}{l}\text { Number of Attributes } \\
\text { per Subject }\end{array}$ & 8.47 & 8.62 & - \\
$\begin{array}{l}\text { Number of Attributes } \\
\text { in Final List }\end{array}$ & 14.00 & 13.83 & - \\
$\begin{array}{l}\text { Mean Rated Importance } \\
\text { of Attributes }\end{array}$ & 1.639 & 1.331 & 3.52 \\
$\begin{array}{l}\text { Number of Important } \\
\text { Attributes }\end{array}$ & 17.83 & 15.00 & 2.56 \\
$\begin{array}{l}\text { Beta Weights in } \\
\text { Regression }\end{array}$ & 0.694 & 0.313 & 3.14 \\
$\begin{array}{l}\text { Standard Deviation of } \\
\text { Ratings }\end{array}$ & 1.095 & 1.129 & - \\
\hline
\end{tabular}


SPORTS (a constituent concept) would be a better predictor of importance for GAMES THAT ARE ALSO SPORTS (where the concept is the qualifier noun) than for SPORTS THAT ARE ALSO GAMES (where it is head noun). The individual beta weights shown in the regression analyses in Table 3 show that for 9 of the 12 concepts this prediction was upheld. The chief exceptions were the two concepts of BUILDINGS and DWELLINGS that unexpectedly produced a strong effect in the reverse direction, with equal weight being given to each constituent in predicting importance for BUILDINGS THAT ARE ALSO DWELLINGS, but only DWELLINGS being predictive for the converse DWELLINGS THAT ARE ALSO BUILDINGS. Because of the varied results for this pair of concepts, the overall effect of noncommutativity was not significant. No explanation for this reversal is readily apparent, so no firm conclusions can be drawn from these data about whether noncommutativity effects occur in attribute importance, paralleling those found in item typicality.

\section{GENERAL DISCUSSION}

The experiments showed that the important attributes defining a conjunction of two concepts are, to a considerable extent, predictable in terms of a model that specifies the inheritance of attributes from the individual constituent concepts. These results help to demonstrate how concept combination might work via a function that combines intensional representations. The hypothesized model proposes that the intension is based on a union of attributes from each constituent, excluding those of low average importance for the constituents, and modified by the need to respect necessity and impossibility. In the General Discussion, I will focus on four particular aspects of the results: dominance in the determination of attribute importance, reasons for inheritance failure, noncompositional attributes, and conflict-based interactions in attribute inheritance.

\section{Dominance}

The results upheld Hampton's (1985b) account of dominance in typicality judgments by showing that the more dominant concepts of each pair had greater numbers of important attributes. In addition, the regression analyses showed unexpectedly that attributes were more important for the conjunction if they were important for the dominant concept than if they were important for the nondominant concept. There were, therefore, two manifestations of the dominance effect in attribute importance, both of which could lead to a conjunction bearing greater similarity to the dominant constituent and, hence, give that constituent a greater value in predicting typicality in the conjunction. First, as originally predicted, dominant concepts had more attributes to be inherited by the conjunction. Second, the importance of an attribute for a conjunction was more likely to resemble its importance for the dominant concept.
The most extreme cases of dominance in the regression equations were the three conjunctions for which only one concept significantly entered the equation. Thus, MACHINES, BUILDINGS, and GAMES did not significantly contribute to their respective conjunctions, MACHINES THAT ARE ALSO VEHICLES, DWELLINGS THAT ARE ALSO BUILDINGS, and GAMES THAT ARE ALSO SPORTS. (In each case, however, the weaker concept did enter the equation significantly for the other form of the conjunction.) It is interesting that in each of these three conjunctions, the attributes of one concept are largely subsumed by those of the other. They have the largest number of overlapping attributes of the six concept pairs $(14,14$, and 13 attributes, respectively, compared with 5,4 , and 9 for the other three conjunctions). Also, membership in the two concept pairs is positively correlated, unlike membership in the other three concept pairs, in which if an item belongs in one set, it is less likely to belong in the other. (In Hampton, 1985b, Experiments 2-4, the correlations across the items usedwhich were not, however, randomly sampled-were all positive for the three pairs in question, mean $r=.15$, and all negative for the remaining pairs, mean $r=-0.45$.) Since typical sports are games, typical dwellings are buildings, and typical vehicles are machines (whereas the converse holds much less well, if at all), the attributes of the latter concept in each conjunction listed above are largely redundant. This is the case even though the concepts in fact overlap and are not related by class inclusion, and it probably explains the large dominance effects observed for these three categories.

Dominance in the determination of attribute importance, as seen in the regression weights, could therefore be related to the degree to which the attributes of the nondominant concept are contained within the set of attributes of the dominant concept. This degree of containment, of course, will also be directly reflected in the relative size of the two attribute sets. To explain the effect on the regression weights, one would then need to propose that common attributes (present in both sets) receive less final importance for the conjunction than do distinctive attributes (important for just one of the concepts). This could be achieved if the averaging function determining importance for the conjunction was not strictly linear. For example, an attribute with importance values that were high for both concepts (a common attribute) would be assigned the average of the two values for its conjunctive importance. An attribute with one high importance value and one low (a distinctive attribute) would, however, be assigned a value greater than the average of the two values. Effectively, this would increase the value of distinctive over the value of common attributes in the intension for the conjunction.

\section{Reasons for Inheritance Failure}

The regression analyses showed that a weighted average of constituent importance provides a reasonable prediction of the importance of an attribute for a conjunction. However, this is obviously only indicative of there 
being some rising function relating conjunctive importance to constituent importances, since any number of functions that increase monotonically with each constituent importance could fit the basic result equally well. In any case, the numerical scale of importance used here is only one of many possible ways of quantifying perceived attribute importance, and has not been established as an interval scale. In fact, the analyses of necessity and impossibility suggest that a simple average will not work when constituent importance is very high or very low. If an attribute has maximal importance for a concept (it is necessary), then a maximum rule applies (the level of importance for the other constituent will have no effect on the importance of the attribute for the conjunction, which will also be very high). Conversely, if an attribute is judged impossible for one constituent, then a minimum rule applies, and again the importance for the other constituent will have no effect on the importance for the conjunction. In collaboration with Mark Gluck at Stanford University, a formula that captures these intuitions has been developed, based on the Dempster-Shafer nule for combining evidence (see Ginsberg, 1984). For attribute importances in the middle range, the formula approximates to an average rule, whereas at either end of the scale, it allows the more extreme score to predominate.

\section{Noncompositionality}

The third important aspect of the results concerns the degree of noncompositionality observed in the data. A methodological point needs to be mentioned here. It is possible that the way in which subjects were asked to list and rate attributes for an explicit conjunction of two concepts, in which each constituent was clearly named, would lead subjects to concentrate on attributes of each individual constituent, perhaps at the expense of other noncompositional attributes of the conjunctive concept. The method used, therefore, may bias the data against noncompositional effects. Bearing in mind that noncompositional effects may be underrepresented in the present data, I will consider these effects, where they did occur, in the following discussion.

The extent to which attributes of a conjunction were not predictable from the attributes of their constituents is revealed in the multiple $R \mathrm{~s}$ of the regression equations and in the data on inheritance of individual attributes. The fit of the regression equations was variable, being very good for some conjunctions (e.g., FURNITUREHOUSEHOLD APPLIANCES), but relatively poor for others (e.g., PETS-BIRDS). The poor fit was not due to low variance or low reliability in the equations and may, therefore, be in part due to noncompositionality.

One source of noncompositionality that causes deviation from the predictions of the inheritance model has been described by Hampton (1985b) as extensional feedback. This mechanism allows that what one knows about the class of objects referred to in a conjunction of two concepts (i.e., the extension of the conjunction) may lead one to associate new attributes with the conjunction that were not associated with either constituent. In this way, there is feedback from experience, or from other stored knowledge, into the newly created conjunctive concept. The more familiar this concept, then the more likely it will be that the attributes associated with it will be unpredictable from knowledge of the attributes of either constituent. PET THAT IS ALSO A BIRD is a much more familiar concept than is FURNITURE THAT IS ALSO A HOUSEHOLD APPLIANCE, with a correspondingly poorer predictive fit of the inheritance model. Analysis of individual attribute inheritance confirmed the noncompositionality of PET-BIRD, with attributes such as lives in cages and is small appearing only in the conjunction.

Extensional feedback comes from familiarity with a conjunction (much as repeated metaphors become crystallized as idioms), and allows us to adapt our concepts to fit our experience. The combination of the attribute sets of concepts to form a composite prototype of their conjunction, therefore, may be a general mechanism for forming new concepts, which does not apply to familiar conjunctions.

Before leaving the discussion of noncompositionality, it is worth mentioning a second possible source of noninherited attributes of conjunctions, which was derived from the theoretical position adopted by Murphy and Medin (1985). If concepts are in fact highly structured theories of a domain, as Murphy and Medin propose, then attributes may be added to the conjunction in order to increase the overall coherence of the composite concept. There was little evidence for such attributes in the data presented here, but some examples can easily be imagined. For example, the average size of a PET FISH is considerably smaller than the average sizes of PETS or of FISH. This disparity might be due to extensional feedback. It could also, however, be due to an inference based on the following premises. Fish need to live in a body of water considerably larger than their own size. Pets live in homes. Homes cannot readily accommodate large bodies of water. Together, these premises can be used to infer a maximum likely size for a pet fish. Thus, in general, an attribute may also be added to the conjunction in order to allow the attributes of the two concepts to form a coherent and sensible concept.

\section{Conflict and Incompatibility}

The final issue to be discussed is the way in which attributes may interact in conjunction formation because of their incompatibility. This idea also relates to the noncompositional view of concept intensions and combinations (see, e.g., Murphy \& Medin, 1985). Holders of this view argue that a concept is not representable simply as a list of independent and unrelated attributes. Rather, each attribute is a part of an interlocking system of understanding, which has been termed a theory (Murphy \& Medin, 1985), a mental model (Gentner \& Stevens, 1983; Johnson-Laird, 1983), or an idealized cognitive model (Lakoff, 1985) of the domain. Thus, we know about PETS that they have owners, live in domestic environments, are cared for and fed, are loved, are warm and cuddly, and provide companionship. Yet these are not unrelated facts. 
The owners share their domestic environment. The pets are loved because they are warm and companionable, they are fed because they do not live in a natural environment where they would find their own food, and so on. To understand the interconnectedness of the different attributes, one has simply to appreciate that one may not be able to change the value of one attribute without at the same time affecting the likelihood, importance, and even interpretation of several others. Malt and Smith (1984) have discussed this fact in the context of showing that the attributes of a concept that are correlated within the concept category tend to assume greater importance in the concept definition.

When two sets of attributes from different concepts are superimposed, there are likely to be several incompatibilities between them which will require resolution so that a conjunction is not a logical impossibility. In the extreme example of the interpretation of noun-noun compounds, such as DUCK-HOUSE or CHAIR-TREE, considerable cognitive effort may be involved in finding a suitable schema that will relate the two noun concepts in a consistent way (Cohen \& Murphy, 1984). For the conjunctions used in this study, at least some of the inheritance failures that were identified can be attributed to this need to render the conjunctive concept coherent. In part, the demonstration of the propagation of impossibility deals with this issue. However, there may be further examples of concept pairs where each concept has an attribute which is possible for the other concept, but where possession of the two attributes together may be impossible, or simply incoherent. For example, is used for construction as an attribute of TOOLS is incompatible with the destructive functions of WEAPONS. The latter attribute is more central to the concept of WEAPONS, so it prevents the inheritance of the TOOL attribute. (We may suppose that destructiveness is more central since tools can have both constructive and destructive functions, whereas weapons are almost always destructive.) Another example is that lives in trees for BIRDS is incompatible with the domestic environment of PETS. In both of these examples, the incompatibility is not a logical impossibility (one could have a domestic environment complete with indoor trees). Instead, it reflects a perceived unlikelihood about the cooccurrence of the two attributes in a normal setting.

At present there is no easy way of demonstrating which of a pair of incompatible attributes will win out and be inherited. However, some recent pilot data I have collected suggest that coherence may be a strong principle in determining the attributes of conjunctions. The aim of the study was simply to provide a measure of the extent to which each attribute of one concept is compatible or incompatible with the attributes of the other concept. The hypothesis was that the importance of an attribute of one concept for the conjunction would be related to the degree of compatibility, as opposed to incompatibility, shown by that attribute to the attributes of the other concept. To test this, the six pairs of concepts were examined to find a conjunction for which there were a sufficient number of distinctive attributes of each concept to give a sensitive test of the hypothesis. The best example was PET BIRD. From the attribute lists, 12 PET attributes and 16 BIRD attributes were chosen on the basis of their showing considerably higher importance for one concept than for the other.

The PET and BIRD attributes were set up as rows and columns of a two-way matrix, and a group of 13 subjects filled in the matrix as follows. They were instructed to take each row attribute in turn and to rate it against each column attribute using a scale from +2 meaning can occur together, and likely to to -2 meaning impossible to occur together. Some subjects worked through the PET attributes, rating each against the BIRD attributes, and others did the converse. The results were very similar for each group, so they were pooled. For each attribute, an average coherence score was calculated, based on the mean ratings given to the attribute, averaged across subjects and across the attributes of the other concept. (Summing vs. averaging across attributes produced very similar results.) To assess the influence of coherence on conjunctive importance, regression analyses were conducted for the two forms of the conjunction, predicting attribute importance for the conjunction from: importance for PETS, importance for BIRDS, and coherence score.

In both equations the coherence scores made significant contributions to the predictive equations. Beta weights for coherence were .32 and .43 for the two equations, significant at .02 and .01 , respectively. Multiple $R \mathrm{~s}$ were .78 and .75 . This small study shows, therefore, that it is indeed likely that coherence versus incompatibility is a determinant of attribute inheritance. Over and above the constituent importance of an attribute, the extent to which it conflicts with the other attributes of the conjoined concept has a significant effect on its importance for the conjunction. (It should however be remembered that PET-BIRD is one of the more familiar and, hence, one of the more noncompositional conjunctions of those studied. Whether similar conflict effects would occur with more novel conjunctions remains to be seen.)

With this result in mind, we can return to the earlier problem of concept dominance. Dominant concepts have a larger number of important attributes. We can speculate that they may also have a stronger degree of coherence, with attributes that are more tightly correlated and interdependent. If so, it would be harder for a conjunction not to inherit an attribute value from the dominant concept than it would be to drop the value from the nondominant concept. This mechanism would predict that inheritance failure should be more common among the attributes of the nondominant concepts. In fact of 36 inheritance failures (using the strict criterion for conjunction importance), 7 were important for both constituents, 17 for a dominant constituent, and 12 for a nondominant constituent. There was, therefore, little evidence in the pattern of individual attribute inheritance for any relation between concept dominance and concept coherence.

Finally, there were some cases in the inheritance data in which attributes appeared to compete, even when they were not strictly incompatible. For instance, MACHINES 
are thought of as being typically electrical, but MACHINES THAT ARE ALSO VEHICLES are not, presumably because of the strong association of VEHICLES with internal combustion engines. FURNITURE is typically decorative, but the strongly practical functions of HOUSEHOLD APPLIANCES rule out this particular quality. Once again, it may be the overall coherence of the conjunctively formed concept which is at the base of these effects.

\section{Conclusion}

In conclusion, good evidence has been provided that one can predict how important an attribute will be in a conjunction from knowledge of its importance in the constituent concepts. As a first approximation, a union is formed of the two attribute sets forming the intensional representation of each concept. Exceptions to a union rule were identified in the cases of attributes with low average constituent importance, attributes judged to be impossible, and attributes where incompatibility leads to deletion of the attribute in order to achieve a more coherent conjunctive concept. For familiar conjunctions, such as PET BIRDS, a number of attributes of the conjunction were identified which were not judged to be attributes of either constituent, and a mechanism of feedback from realworld knowledge was posited to account for this.

There was also good evidence for a parallelism between the extensional phenomenon of how item typicality in a conjunction is determined, and the intensional phenomenon of how attribute importance is determined for the same conjunction. This parallelism bodes well for current attempts to treat conceptual combination within an intensional framework (Hampton, 1983, 1985b; Smith \& Osherson, 1984).

\section{REFERENCES}

Cohen, B., \& Murphy, G. L. (1984). Models of concepts. Cognitive Science, 8, 27-58.

Gentner, D., \& Stevens, A. L. (Eds.). (1983). Mental models. Hillsdale, NJ: Erlbaum.

GiNSBERG, M. L. (1984). Non-monotonic reasoning using Dempster's rule (Heuristic Programming Project Report No. 84-30). Stanford, CA: Stanford University.

HAMPTON, J. A. (1979). Polymorphous concepts in semantic memory.
Journal of Verbal Learning \& Verbal Behavior, 18, 441-461.

HAMPTON, J. A. (1981). An investigation of the nature of abstract concepts. Memory \& Cognition, 9, 149-156.

Hampton, J. A. (1983). A composite prototype model of conceptual conjunction. Unpublished manuscript, The City University, London.

Hampton, J. A. (1985a, November). Combination of natural concepts. Paper presented at the 26th Annual Meeting of the Psychonomic Society, Boston.

HAMPTON, J. A . (1985b). Overextension of conjunctive concepts: Evidence for a unitary model of concept typicality and class inclusion. Manuscript under review. The City University, London.

JohnSON-LAIRD, P. N. (1983). Mental models: Towards a cognitive science of language, inference, and consciousness. Cambridge, England: Cambridge University Press.

JONES, G. V. (1982). Stacks not fuzzy sets: An ordinal basis for prototype theory of concepts. Cognition, 12, 281-290.

LAKOFF, G. (1985). Women, fire and dangerous things. Chicago: University of Chicago Press

MaLT, B. C., \& SMIth, E. E. (1984). Correlated properties in natural categories. Journal of Verbal Learning \& Verbal Behavior, 23, 250-269

MCNamara, T. P., \& Sternberg, R. (1983). Mental models of word meaning. Journal of Verbal Leaming \& Verbal Behavior, 22, 449-474.

MURPHY, G. L., \& MEdIN, D. L. (1985). The role of theories in conceptual coherence. Psychological Review, 92, 289-316.

OrTony, A., Vondruska, R. J., Foss, M. A., \& Jones, L. E. (1985). Salience, similes, and the asymmetry of similarity. Joumal of Memory \& Language, 24, 569-594.

OSHERSON, D. N., \& SMITH, E. E. (1981). On the adequacy of prototype theory as a theory of concepts. Cognition, 11, 35-58.

OSHERSON, D. N., \& SMITH, E. E. (1982). Gradedness and conceptual conjunction. Cognition, 12, 299-318.

RoscH, E. (1975). Cognitive representations of semantic categories Journal of Experimental Psychology: General, 104, 192-233.

Rosch, E., \& MERvis, C. B. (1975). Family resemblances: Studies in the internal structure of categories. Cognitive Psychology, 7, 573-605. SMITH, E. E., \& OSHERSON, D. N. (1984). Conceptual combination with prototype concepts. Cognitive Science, 8, 337-361.

Smith, E. E., Osherson, D. N., Rups, L. J., Albert, K., \& KeAne, M (1985). Combining prototypes: A modification model. Unpublished manuscript, Bolt, Beranek, \& Newman, Camridge, MA.

Thagard, P. (1983, June). Conceptual combination: A frame-based theory. Paper presented at the Society for Philosophy and Psychology, Wellesley, MA.

ThaGaRd, P. (1984). Conceptual combination and scientific discovery. In P. Asquith \& P. Kitcher (Eds.), PSA (Vol. 1). East Lansing, MI: Philosophy of Science Association.

TURKSEN, I. B. (1984). Combination of concepts. Unpublished manuscript, University of Toronto.

ZADEH, L. (1965). Fuzzy sets. Information \& Control, 8, 338-353.

ZADEH, L. (1982). A note on prototype theory and fuzzy sets. Cognition, 12, 291-297.

\section{APPENDIX}

Lists of Attributes Generated in Experiment 1 that Were Used for Ratings in Experiment 2, for Each Concept Pair

1. FURNITURE AND HOUSEHOLD APPLIANCES

\begin{tabular}{|c|c|c|c|c|c|c|c|c|}
\hline \multirow[b]{2}{*}{ Attribute } & \multicolumn{2}{|c|}{ Furniture } & \multicolumn{2}{|c|}{$\begin{array}{l}\text { Household } \\
\text { Appliances }\end{array}$} & \multicolumn{2}{|c|}{$\begin{array}{l}\text { Furniture } \\
\text { that is also a } \\
\text { H. Appliance }\end{array}$} & \multicolumn{2}{|c|}{$\begin{array}{l}\text { H. Appliances } \\
\text { that are also } \\
\text { Furniture }\end{array}$} \\
\hline & $\mathrm{PF}$ & MR & $\mathrm{PF}$ & MR & $\mathrm{PF}$ & MR & $\mathrm{PF}$ & MR \\
\hline Is used by people & 9 & 2.00 & 8 & 2.87 & 5 & 3.00 & 8 & 2.37 \\
\hline Is found in buildings & 6 & 1.50 & 4 & 0.87 & 4 & 2.37 & 5 & 1.87 \\
\hline Is for sitting on & 6 & 1.12 & 0 & -1.00 & 1 & -0.87 & 3 & -0.12 \\
\hline Is for comfort & 5 & 2.50 & 1 & 1.25 & 1 & 1.87 & 2 & 1.75 \\
\hline Is wooden & 5 & 1.37 & 0 & -0.87 & $i$ & -0.50 & 1 & -0.37 \\
\hline
\end{tabular}


APPENDIX (Continued)

\begin{tabular}{|c|c|c|c|c|c|c|c|c|}
\hline \multirow[b]{2}{*}{ Attribute } & \multicolumn{2}{|c|}{ Furniture } & \multicolumn{2}{|c|}{$\begin{array}{l}\text { Household } \\
\text { Appliances }\end{array}$} & \multicolumn{2}{|c|}{$\begin{array}{l}\text { Furniture } \\
\text { that is also a } \\
\text { H. Appliance }\end{array}$} & \multicolumn{2}{|c|}{$\begin{array}{l}\text { H. Appliances } \\
\text { that are also } \\
\text { Furniture }\end{array}$} \\
\hline & $\mathrm{PF}$ & MR & $\mathrm{PF}$ & MR & PF & MR & PF & MR \\
\hline Is used for storage & 5 & -0.62 & 0 & -0.62 & 0 & -0.50 & 2 & 0.75 \\
\hline Is an object & 5 & 2.75 & 0 & 2.75 & 0 & 2.75 & 0 & 1.75 \\
\hline Supports other objects & 4 & 1.00 & 1 & 0.25 & 1 & 0.25 & 0 & 0.50 \\
\hline Is found in the home & 3 & 2.12 & 4 & 2.62 & 1 & 3.25 & 4 & 2.37 \\
\hline Is made of metal & 3 & -0.25 & 2 & 1.12 & 3 & 1.00 & 1 & 0.12 \\
\hline Is manmade & 3 & 2.25 & 2 & 2.50 & 0 & 1.75 & 0 & 1.75 \\
\hline Is for sleeping on & 3 & 1.00 & 0 & -1.37 & 0 & -0.87 & 0 & -0.50 \\
\hline Is made with cloth & 3 & -0.12 & 0 & -1.75 & 0 & -1.00 & 0 & -0.87 \\
\hline Makes life easier & 1 & 1.12 & 8 & 2.87 & 1 & 2.87 & 0 & 2.00 \\
\hline Is useful & 1 & 1.87 & 6 & 2.50 & 3 & 1.50 & 8 & 2.50 \\
\hline Performs a task or job & 0 & 1.37 & 5 & 3.12 & 4 & 3.12 & 2 & 2.75 \\
\hline Is expensive & 0 & 1.25 & 5 & 1.50 & 2 & 1.25 & 1 & 1.00 \\
\hline Is for preparing food & 0 & -1.25 & 5 & 0.75 & 1 & 0.75 & 2 & 0.62 \\
\hline Is used for cleaning & 0 & -1.62 & 5 & 0.62 & 1 & -0.25 & 0 & -0.50 \\
\hline Is electrical & 0 & -1.25 & 4 & 1.87 & 8 & 1.50 & 3 & 0.87 \\
\hline Is fast & 0 & -1.87 & 4 & 0.62 & 0 & 0.50 & 1 & -0.12 \\
\hline Has various colors & 0 & 1.50 & 3 & 0.62 & 1 & 1.25 & 3 & 0.87 \\
\hline Is large & 2 & 0.25 & 1 & 0.75 & 1 & 0.75 & 3 & 0.50 \\
\hline Is decorative & 2 & 2.00 & 0 & -0.25 & 1 & 0.25 & 6 & 0.87 \\
\hline Is powered & 0 & -1.00 & 2 & 2.50 & 0 & 1.50 & 3 & 0.50 \\
\hline Has a light & 0 & -0.87 & 0 & 0.00 & 3 & 0.00 & 2 & 0.00 \\
\hline
\end{tabular}

2. MACHINES AND VEHICLES

\begin{tabular}{|c|c|c|c|c|c|c|c|c|}
\hline \multirow[b]{2}{*}{ Attribute } & \multicolumn{2}{|c|}{ Machines } & \multicolumn{2}{|c|}{ Vehicles } & \multicolumn{2}{|c|}{$\begin{array}{l}\text { Machines } \\
\text { that are also } \\
\text { Vehicles }\end{array}$} & \multicolumn{2}{|c|}{$\begin{array}{l}\text { Vehicles } \\
\text { that are also } \\
\text { Machines }\end{array}$} \\
\hline & $\mathrm{PF}$ & MR & $\mathrm{PF}$ & MR & $\mathrm{PF}$ & $\mathrm{MR}$ & PF & MR \\
\hline Is used by people & 8 & 3.00 & 6 & 3.00 & 2 & 2.00 & 6 & 3.37 \\
\hline Performs a task & 8 & 3.37 & 1 & 2.37 & 1 & 2.37 & 2 & 2.75 \\
\hline Is powered & 6 & 3.00 & 4 & 2.50 & 5 & 2.87 & 5 & 2.87 \\
\hline Is manmade & 6 & 2.12 & 4 & 1.50 & 3 & 2.12 & 4 & 2.25 \\
\hline Makes life easier & 6 & 2.50 & 4 & 1.75 & 1 & 2.12 & 1 & 2.75 \\
\hline Is fast & 6 & 1.75 & 3 & 1.87 & 5 & 1.50 & 3 & 1.12 \\
\hline Is made of metal & 4 & 1.75 & 1 & 1.75 & 1 & 2.25 & 5 & 2.00 \\
\hline Needs maintenance & 4 & 2.87 & 0 & 1.87 & 1 & 2.12 & 2 & 2.87 \\
\hline Uses energy or fuel & 3 & 2.50 & 3 & 2.75 & 7 & 2.87 & 5 & 3.12 \\
\hline Can be dangerous & 3 & 2.12 & 1 & 1.87 & 1 & 2.25 & 2 & 2.25 \\
\hline Is technological & 3 & 2.12 & 1 & 2.12 & 0 & 1.87 & 1 & 2.75 \\
\hline Is noisy & 3 & 1.37 & 0 & 1.00 & 2 & 1.25 & 1 & 1.25 \\
\hline Is electrical & 3 & 2.37 & 0 & 0.62 & 2 & 1.25 & 0 & 0.12 \\
\hline Is used in industry & 3 & 2.87 & 0 & 1.75 & 0 & 1.25 & 1 & 2.25 \\
\hline Speeds up life & 3 & 1.50 & 0 & 1.57 & 0 & 1.12 & 1 & 1.50 \\
\hline Replaces people & 3 & 2.00 & 0 & -1.00 & 0 & 0.00 & 0 & 0.62 \\
\hline Moves along & 1 & 0.12 & 9 & 2.37 & 6 & 2.12 & 5 & 2.62 \\
\hline Is for transportation & 0 & 0.00 & 7 & 3.12 & 4 & 3.25 & 5 & 3.12 \\
\hline Carries people & 0 & 0.37 & 6 & 1.87 & 6 & 2.00 & 0 & 1.75 \\
\hline Is operated & 4 & 3.00 & 4 & 3.00 & 4 & 2.62 & 4 & 3.37 \\
\hline Goes from place to place & 0 & 0.00 & 4 & 2.62 & 2 & 3.37 & 1 & 3.00 \\
\hline Lets people go faster & 0 & 2.50 & 4 & 2.25 & 0 & 2.37 & 1 & 2.87 \\
\hline Is owned by someone & 0 & 0.87 & 3 & 1.86 & 0 & 1.50 & 0 & 2.75 \\
\hline Is complex & 2 & 2.12 & 0 & 1.25 & 0 & 1.62 & 3 & 2.00 \\
\hline Carries things & 0 & 0.50 & 2 & 2.37 & 4 & 2.50 & 2 & 2.00 \\
\hline Runs on roads, tracks & 0 & 0.25 & 2 & 2.25 & 3 & 2.50 & 0 & 2.25 \\
\hline Has wheels & 0 & 0.50 & 1 & 2.50 & 6 & 2.87 & 5 & 2.12 \\
\hline Has seats & 0 & 0.00 & 0 & 1.75 & 5 & 1.87 & 0 & 2.12 \\
\hline Is large & 0 & 1.00 & 0 & 1.00 & 3 & 1.37 & 2 & 1.75 \\
\hline Has brakes & 0 & 0.37 & 0 & 2.37 & 3 & 2.37 & 1 & 2.75 \\
\hline
\end{tabular}


APPENDIX (Continued)

3. BIRDS AND PETS

Birds Pets

that are also that are also

\begin{tabular}{|c|c|c|c|c|c|c|c|c|}
\hline \multirow[b]{2}{*}{ Attribute } & \multicolumn{2}{|c|}{ Birds } & \multicolumn{2}{|c|}{ Pets } & \multicolumn{2}{|c|}{ Pets } & \multicolumn{2}{|c|}{ Birds } \\
\hline & $\mathrm{PF}$ & MR & PF & $\mathrm{MR}$ & PF & MR & PF & MR \\
\hline Sings & 8 & 1.62 & 0 & 0.25 & 4 & 1.12 & 4 & 1.87 \\
\hline Flies & 7 & 2.62 & 0 & 0.25 & 3 & 2.25 & 6 & 3.25 \\
\hline Has feathers & 6 & 3.62 & 0 & 0.00 & 5 & 3.25 & 8 & 3.25 \\
\hline Lays eggs & 6 & 3.12 & 0 & 0.25 & 0 & 1.12 & 3 & 0.75 \\
\hline Is an animal & 5 & 3.00 & 6 & 3.25 & 0 & 2.50 & 1 & 2.37 \\
\hline Has a beak & 5 & 3.12 & 0 & 0.25 & 3 & 3.25 & 7 & 3.25 \\
\hline Has wings & 5 & 3.50 & 0 & 0.25 & 2 & 3.37 & 5 & 3.25 \\
\hline Chirps & 5 & 2.62 & 0 & 0.25 & 2 & 2.12 & 4 & 2.87 \\
\hline Builds nests & 5 & 3.75 & 0 & -0.37 & 0 & 0.00 & 1 & 0.62 \\
\hline Is carnivorous & 5 & 0.00 & 0 & 0.37 & 0 & -0.50 & 0 & -0.75 \\
\hline Is small & 4 & 0.87 & 0 & 1.12 & 4 & 2.12 & 2 & 1.62 \\
\hline Eats worms & 4 & 2.25 & 0 & 0.00 & 0 & 0.87 & 0 & 1.37 \\
\hline Has two legs & 4 & 2.87 & 0 & 0.25 & 0 & 3.25 & 0 & 2.87 \\
\hline Is pretty & 3 & 1.25 & 3 & 0.75 & 1 & 1.50 & 1 & 1.37 \\
\hline Is colorful & 3 & 1.62 & 0 & 0.50 & 4 & 1.37 & 4 & 2.00 \\
\hline Are of different sizes & 3 & 3.00 & 0 & 1.87 & 0 & 2.62 & 1 & 2.12 \\
\hline Lives in trees & 3 & 2.75 & 0 & -0.43 & 0 & 0.25 & 1 & 0.62 \\
\hline Migrates & 3 & 2.25 & 0 & -1.25 & 0 & -1.12 & 0 & -0.12 \\
\hline Is lightweight & 3 & 1.62 & 0 & 0.25 & 0 & 2.25 & 0 & 1.75 \\
\hline Is free & 3 & 1.75 & 0 & 0.00 & 0 & -0.62 & 0 & 0.00 \\
\hline Is common & 3 & 1.87 & 0 & 2.25 & 0 & 0.50 & 0 & 1.12 \\
\hline Is cared for, dependent & 0 & -0.12 & 6 & 2.50 & 3 & 2.62 & 5 & 2.50 \\
\hline Provides companionship & 0 & 0.37 & 6 & 2.75 & 0 & 1.75 & 0 & 1.75 \\
\hline Is friendly & 0 & 0.50 & 5 & 1.87 & 0 & 1.12 & 0 & 1.62 \\
\hline Provides security & 0 & -0.50 & 5 & 1.75 & 0 & -0.87 & 0 & -0.25 \\
\hline Lives in a domestic home & 0 & -0.25 & 4 & 2.75 & 3 & 1.87 & 1 & 2.00 \\
\hline Is enjoyed & 1 & 0.75 & 4 & 1.75 & 3 & 1.87 & 0 & 1.87 \\
\hline Is loved & 0 & 0.25 & 4 & 2.00 & 0 & 1.50 & 1 & 1.50 \\
\hline Is kept by an owner & 0 & -0.25 & 3 & 3.12 & 5 & 3.25 & 7 & 2.62 \\
\hline Is playful & 0 & 0.50 & 3 & 1.87 & 1 & 0.87 & 1 & 1.12 \\
\hline Is cuddly & 0 & -0.62 & 3 & 1.00 & 0 & -0.50 & 0 & -0.75 \\
\hline Is alive & 0 & 3.25 & 3 & 2.87 & 0 & 3.37 & 0 & 3.12 \\
\hline Has claws & 2 & 1.00 & 0 & 0.75 & 3 & 1.25 & 4 & 2.12 \\
\hline Eats birdseed & 1 & 1.62 & 0 & 0.00 & 4 & 1.62 & 5 & 3.00 \\
\hline Is tame & 0 & -0.12 & 2 & 2.12 & 4 & 1.87 & 3 & 2.00 \\
\hline Is trained & 0 & -0.12 & 1 & 1.75 & 3 & 1.62 & 3 & 1.25 \\
\hline Is kept in a cage & 0 & 1.00 & 0 & 0.12 & 5 & 2.00 & 7 & 2.50 \\
\hline Talks & 0 & -0.75 & 0 & -0.75 & 5 & -0.50 & 2 & -0.12 \\
\hline
\end{tabular}

4. BUILDINGS AND DWELLINGS

\begin{tabular}{|c|c|c|c|c|c|c|c|c|}
\hline \multirow[b]{2}{*}{ Attribute } & \multicolumn{2}{|c|}{ Buildings } & \multicolumn{2}{|c|}{ Dwellings } & \multicolumn{2}{|c|}{$\begin{array}{l}\text { Buildings } \\
\text { that are also } \\
\text { Dwellings }\end{array}$} & \multicolumn{2}{|c|}{$\begin{array}{l}\text { Dwellings } \\
\text { that are also } \\
\text { Buildings }\end{array}$} \\
\hline & PF & MR & PF & MR & PF & MR & PF & MR \\
\hline Is large & 6 & 2.25 & 0 & 1.37 & 1 & 2.87 & 3 & 2.12 \\
\hline Is lived in & 5 & 1.00 & 9 & 3.37 & 6 & 3.25 & 5 & 3.00 \\
\hline Is built & 5 & 3.12 & 2 & 2.25 & 2 & 3.62 & 3 & 2.75 \\
\hline Has a door & 5 & 2.50 & 0 & 2.62 & 5 & 3.12 & 3 & 3.25 \\
\hline Is tall & 5 & 0.87 & 0 & 0.50 & 0 & 1.75 & 2 & 1.25 \\
\hline Is protection from & & & & & & & & \\
\hline the environment & 4 & 2.37 & 6 & 3.12 & 2 & 3.50 & 2 & 3.25 \\
\hline Is manmade & 4 & 3.25 & 2 & 2.12 & 4 & 3.25 & 3 & 2.50 \\
\hline Is used by people & 4 & 2.37 & 2 & 2.12 & 3 & 3.12 & 0 & 2.50 \\
\hline Is costly & 4 & 1.12 & 1 & 1.50 & 0 & 2.25 & 1 & 1.87 \\
\hline Has windows & 4 & 2.12 & 0 & 1.75 & 5 & 2.50 & 4 & 2.00 \\
\hline
\end{tabular}


APPENDIX (Continued)

\begin{tabular}{|c|c|c|c|c|c|c|c|c|}
\hline \multirow[b]{2}{*}{ Attribute } & \multicolumn{2}{|c|}{ Buildings } & \multicolumn{2}{|c|}{ Dwellings } & \multicolumn{2}{|c|}{$\begin{array}{c}\text { Buildings } \\
\text { that are also } \\
\text { Dwellings }\end{array}$} & \multicolumn{2}{|c|}{$\begin{array}{c}\text { Dwellings } \\
\text { that are also } \\
\text { Buildings }\end{array}$} \\
\hline & PF & $\mathbf{M R}$ & PF & MR & PF & MR & PF & MR \\
\hline Contains offices & 4 & 1.00 & 0 & 0.12 & 0 & 0.25 & 2 & 0.75 \\
\hline Has rooms & 3 & 2.62 & 1 & 2.62 & 5 & 3.12 & 4 & 2.87 \\
\hline Has floors & 3 & 2.75 & 1 & 2.87 & 1 & 3.00 & 3 & 2.12 \\
\hline Is stable & 3 & 2.37 & 1 & 1.37 & 1 & 2.62 & 1 & 2.37 \\
\hline Is found in cities & 3 & 2.25 & 0 & 0.87 & 1 & 2.37 & 3 & 2.12 \\
\hline Is strong & 3 & 2.12 & 0 & 1.50 & $\mathbf{0}$ & 2.37 & 1 & 2.50 \\
\hline Is imposing & 3 & 0.12 & 0 & -0.37 & 0 & 0.00 & 1 & 0.00 \\
\hline Is a shelter & 2 & 2.50 & 7 & 3.75 & 1 & 3.50 & 2 & 3.25 \\
\hline Is a place & 0 & 2.75 & 6 & 3.25 & 1 & 2.87 & 3 & 2.62 \\
\hline Is for families & 0 & 0.12 & 4 & 1.50 & 3 & 1.25 & 1 & 2.12 \\
\hline Is a home & 1 & 0.62 & 3 & 2.87 & 1 & 2.25 & 1 & 3.12 \\
\hline Is for sleeping in & 0 & 0.37 & 3 & 2.75 & 4 & 1.75 & 3 & 2.87 \\
\hline Is a possession & 0 & 1.62 & 3 & 2.12 & 1 & 1.75 & 1 & 1.75 \\
\hline Gives security & 0 & 1.87 & 3 & 2.25 & 1 & 2.87 & 1 & 2.50 \\
\hline Is for animals and people & 0 & 0.29 & 3 & 1.87 & 1 & 1.87 & 0 & 1.25 \\
\hline Is wooden & 0 & 0.87 & 1 & 0.50 & 0 & 0.50 & 3 & 0.37 \\
\hline Has a kitchen & 0 & 0.50 & 0 & 2.12 & 5 & 2.50 & 0 & 3.00 \\
\hline Has a bathroom & 0 & 2.00 & 0 & 1.87 & 4 & 2.62 & 1 & 2.50 \\
\hline Is decorated & 0 & 1.62 & 0 & 1.25 & 3 & 2.25 & 0 & 1.75 \\
\hline
\end{tabular}

\section{TOOLS AND WEAPONS}

\begin{tabular}{|c|c|c|c|c|c|c|c|c|}
\hline \multirow[b]{2}{*}{ Attribute } & \multicolumn{2}{|c|}{ Tools } & \multicolumn{2}{|c|}{ Weapons } & \multicolumn{2}{|c|}{$\begin{array}{c}\text { Tools } \\
\text { that are also } \\
\text { Weapons }\end{array}$} & \multicolumn{2}{|c|}{$\begin{array}{c}\text { Weapons } \\
\text { that are also } \\
\text { Tools } \\
\end{array}$} \\
\hline & PF & MR & PF & MR & PF & MR & PF & MR \\
\hline Is used by people & 8 & 2.75 & 9 & 3.62 & 8 & 2.37 & 7 & 3.50 \\
\hline Are of various types & 7 & 2.00 & 0 & 2.75 & 0 & 2.12 & 1 & 2.62 \\
\hline $\begin{array}{l}\text { Helps one accomplish } \\
\text { a task }\end{array}$ & 6 & 3.25 & 0 & 0.50 & 1 & 1.50 & 2 & 2.25 \\
\hline Is useful & 6 & 2.50 & 0 & -0.12 & 1 & 2.12 & 1 & 2.75 \\
\hline Is manmade & 5 & 2.25 & 3 & 2.50 & 1 & 1.37 & 2 & 2.00 \\
\hline Is made of metal & 5 & 2.00 & 0 & 1.75 & 3 & 2.00 & 3 & 1.75 \\
\hline Are of different shapes & 3 & 2.00 & 6 & 2.87 & 0 & 1.87 & 1 & 2.25 \\
\hline Is hand-held & 3 & 1.25 & 0 & 1.62 & 7 & 2.00 & 4 & 2.00 \\
\hline Is durable, strong & 3 & 1.75 & 0 & 1.50 & 4 & 1.75 & 0 & 2.00 \\
\hline Is used for construction & 3 & 1.62 & 0 & -1.25 & 2 & 1.00 & 5 & 0.37 \\
\hline Is complicated & 3 & -0.25 & 0 & 0.62 & 0 & -0.75 & 1 & -0.25 \\
\hline Is used to increase & & & & & & & & \\
\hline one's power & 2 & 1.87 & 6 & 2.75 & 2 & 1.12 & 0 & 1.87 \\
\hline Is used for killing & 0 & -1.00 & 6 & 2.12 & 1 & 1.37 & 3 & 0.62 \\
\hline Is used for defense & 1 & 0.00 & 5 & 2.62 & 1 & 1.87 & 2 & 1.75 \\
\hline Is used to injure people & 0 & -0.75 & 4 & 2.25 & 2 & 2.50 & 1 & 1.37 \\
\hline Is for hunting with & 0 & -0.50 & 4 & 1.37 & 0 & 1.37 & 1 & 1.37 \\
\hline Is used for threat & & & & & & & & \\
\hline or coercion & 0 & -0.75 & 4 & 2.50 & 0 & 0.62 & 0 & 2.00 \\
\hline Is an object & 2 & 2.62 & 3 & 3.00 & 1 & 2.37 & 0 & 3.37 \\
\hline Can be dangerous & 1 & 1.50 & 3 & 3.62 & 3 & 2.75 & 2 & 3.37 \\
\hline Is used in war & 0 & -0.50 & 3 & 2.62 & 0 & 0.37 & 0 & 1.62 \\
\hline Performs a task quickly & 2 & 1.62 & 0 & 1.12 & 3 & 1.00 & 0 & 1.50 \\
\hline Has a handle & 1 & 1.50 & 0 & 1.25 & 4 & 1.50 & 1 & 1.75 \\
\hline Is sharp & 0 & 1.12 & 0 & 1.12 & 8 & 1.87 & 8 & 1.12 \\
\hline Has a blade for cutting & 0 & -0.25 & 0 & 0.37 & 5 & 1.75 & 4 & 0.75 \\
\hline Is heavy & 0 & -0.25 & 0 & 0.25 & 5 & 0.75 & 3 & 1.12 \\
\hline Has a point & 0 & 0.50 & 0 & 0.87 & 4 & 1.75 & 1 & 1.25 \\
\hline Is blunt & 0 & 0.37 & 0 & -0.12 & 0 & -0.37 & 3 & 0.12 \\
\hline
\end{tabular}




\section{SPORTS AND GAMES}

Sports Games

that are also that are also

\begin{tabular}{|c|c|c|c|c|c|c|c|c|}
\hline \multirow[b]{2}{*}{ Attribute } & \multicolumn{2}{|c|}{ Sports } & \multicolumn{2}{|c|}{ Games } & \multicolumn{2}{|c|}{ Games } & \multicolumn{2}{|c|}{ Sports } \\
\hline & $\mathrm{PF}$ & MR & PF & MR & $\mathrm{PF}$ & MR & $\mathrm{PF}$ & MR \\
\hline \multicolumn{9}{|l|}{ Is done for fun } \\
\hline Is for two or more people & 7 & $\begin{array}{l}2.02 \\
1.12\end{array}$ & 5 & 2.00 & 7 & 2.12 & 3 & 1.75 \\
\hline Uses skills & 6 & 2.62 & 5 & 2.75 & 1 & 3.12 & 3 & 2.50 \\
\hline \multicolumn{9}{|l|}{ Is done professionally } \\
\hline for money & 6 & 1.25 & 0 & 1.12 & 3 & 0.25 & 1 & 1.87 \\
\hline Is a physical activity & 5 & 3.50 & 5 & 1.12 & 6 & 3.62 & 7 & 3.00 \\
\hline \multicolumn{9}{|l|}{ Is physical exercise, } \\
\hline Has spectators & 5 & 1.12 & 1 & 0.87 & 5 & $\begin{array}{l}2.02 \\
1.87\end{array}$ & 3 & 1.75 \\
\hline Is for health and fitness & 5 & 2.37 & 0 & 1.87 & 1 & 2.12 & 1 & 2.75 \\
\hline Has rules & 4 & 2.37 & 5 & 3.00 & 4 & 2.87 & 6 & 3.37 \\
\hline Is a recreational pastime & 4 & 2.00 & 5 & 3.37 & 0 & 2.50 & 0 & 2.37 \\
\hline Involves competition & 4 & 2.25 & 4 & 3.00 & 7 & 2.50 & 6 & 3.12 \\
\hline Is for relaxation & 3 & 1.62 & 4 & 1.87 & 0 & 1.87 & 0 & 1.37 \\
\hline Is exciting & 3 & 1.75 & 2 & 2.00 & 0 & 2.25 & 1 & 2.12 \\
\hline Is challenging & 3 & 2.12 & 2 & 2.75 & 0 & 2.62 & 1 & 2.25 \\
\hline Is played with friends & 3 & 1.75 & 1 & 1.87 & 1 & 1.75 & 0 & 1.75 \\
\hline \multicolumn{9}{|l|}{ Involves mental } \\
\hline concentration & 0 & 2.25 & 6 & 2.25 & 4 & 2.25 & 2 & 2.12 \\
\hline Has an object or goal & 0 & 2.75 & 5 & 3.62 & 3 & 3.00 & 2 & 2.62 \\
\hline \multicolumn{9}{|l|}{ Has a goal which } \\
\hline is not serious & 0 & 0.50 & 5 & 2.00 & 0 & 1.00 & 0 & 0.62 \\
\hline Involves teams & 2 & 1.12 & 1 & 1.62 & 9 & 1.25 & 7 & 1.75 \\
\hline Involves equipment & 2 & 1.75 & 1 & 1.00 & 2 & 2.37 & 6 & 2.12 \\
\hline Uses a ball & 2 & 1.12 & 0 & 0.62 & 1 & 1.37 & 3 & 1.25 \\
\hline Has a time limit & 1 & 1.00 & 0 & 0.62 & 3 & 1.00 & 3 & 1.00 \\
\hline Has a referee & 1 & 1.25 & 0 & 1.12 & 3 & 1.12 & 1 & 1.12 \\
\hline Involves athletic ability & 1 & 2.37 & 0 & 1.50 & 1 & 1.75 & 4 & 2.37 \\
\hline
\end{tabular}

Note-Production frequency (PF) and mean rated importance (MR) for each of the two constituents and two conjunctions.

(Manuscript received June 4, 1985;

revision accepted for publication May 27, 1986.) 